Journal of Qualitative Criminal Justice \& Criminology

\title{
Book Review | The Stickup \\ Kids: Race, Drugs, Violence, \\ and the American Dream
}

Robert J. Durán ${ }^{1}$

${ }^{1}$ University of Tennessee

Published on: Oct 01, 2014

DOI: $10.21428 / 88 d e 04 a 1.2 d 2 a 6 b 2 f$

License: Creative Commons Attribution 4.0 International License (CC-BY 4.0). 
Randol Contreras. The Stickup Kids: Race, Drugs, Violence, and the American Dream. University of California Press, 2013; 272 pp.; ISBN: 9780520273382.

Most academics do not live in segregated black or Latino communities that contain higher rates of violence and incarceration. Historically, ethnographers have attempted to bridge this gap, but only a small number of these researchers match the populations they are studying in terms of age, class, ethnicity, and gender. An even rarer ethnographer comes from these same neighborhoods and shares lifelong friendships with the participants. Randol Contreras's Stickup Kids provides an in-your-face portrayal of a drug dealing crew turned drug robbers in the South Bronx of New York City during the late 1980s and early 1990s. Due to structural changes in the drug market, several young Dominican entrepreneurs sought other ways to maintain their previous high-spending lifestyle. Contreras presents an insider account of 27 people that is hard-hitting, gravitating, and reflexive. In this book review, I will outline my interest in this book, some of the major themes presented, and some issues deserving increased attention.

In the fall of 2013, I was preparing to teach a graduate course on Juvenile Justice and I came across Contreras's recently released book. The title included Kids, and my assumption was that it might provide an excellent opportunity to expose students to an ethnography of youth violence. The actual outcome was more of a longitudinal opportunity to get my students thinking about marginal lives and individual changes over time. I used other books that primarily focused on the years of adolescence and only a small number of studies offer the breadth to cover the highs and lows of young men and women as they age over time. As I began reading, I became a little bit inquisitive-who is Randol Contreras? As an urban ethnographer, with previous ties to gang membership, drug markets, and having had experience as a robbery victim, the best way to develop an understanding of who someone is, in my eyes, to meet and talk with that individual in person. I made sure to attend Randol's presentations at the 2013 annual American Society of Criminology conference. Randol presented himself as an articulate, intelligent, and soft-spoken individual whom I believed could have maintained the type of personality to conduct this research study. My students were eager to hear my evaluation since they loved the book. As levels of drug related violence on the U.S.-Mexico Border began to decrease, none of the other books assigned captured the same interest of my students who were living in a geographic area located between some of the lowest levels of violence in the United States (El Paso, Texas) and the highest levels of violence in the world (Ciudad Juárez, Mexico).

Dr. Contreras organized The Stickup Kids into three parts. The first part focused on establishing a historical and geographic context for which the rise and fall of crack cocaine took place. Then it moves into the dynamics of a drug robbery and finally to the outcome of the participants in the study. Dr. 
Contreras's book captured the interest of my students and me primarily by offering three contributions. First, the style of writing presents an insider version that is similar to Philippe Bourgois's (1995) In Search of Respect. The entire book provides a conversation between Randol and his friends who were engaged in drug dealing and later a drug robbery lifestyle. Rather than providing blocked sections of quotes, the dialogue is interwoven into the narrative. The primary two characters are Gus and Pablo who are hoping to attain the American Dream. Second, because Randol has known these individuals from childhood, he is able to analyze longer periods of their lives. This allows for the participants and Randol himself to be comfortable both in the context of where the study is located and for the ease in which the young men share information-an ethnographic accomplishment that allows for a clearer overview of the highs and lows of an individuals' life. Contreras compares this insider knowledge with the literature on drug robbers, especially the work of Jack Katz (1990). Katz focused on the emotional thrills of participating in violence whereas Contreras situated these stories into a geographic context and time period and by outlining the marginalized social position of the participants. The third point of interest is the airing of dirty laundry, which at times made me cognizant of the difficulties for members of underrepresented groups to share their stories while ensuring they are not generalized into already accepted stereotypes. However, it helped make the study more realistic by describing real world situations in which masculinity and violence are reenacted through a stratified society plagued with racial inequality. Randol himself described this as a standpoint crisis, and he struggled whether readers might view such a portrayal as vilifying the larger Dominican community. His goal was to show the complete view of human beings and what events led to their present situation.

There were some issues that deserved increased attention, but I attributed this more to the restraints of trade presses, university presses, and page limits that Randol alluded to under the heading of Danger, Writing, and Representation in the Introduction. This omission of material led to an abrupt shift from part two to part three. Although there were five chapters in part one and part two, there was only one chapter in part three. I thought there needed to be more chapters or information provided to outline the reasons for the fall of the drug crew turned drug robbers and more analysis in the conclusion. The solutions were quickly introduced and not developed. In the final chapters, I would have also liked to read more about issues of race and ethnicity that were introduced in Chapter Four "The New York Boys" and the role of an insider in creating solutions.

Overall, Randol Contreras's book the Stickup Kids pushed me in many ways. It made me reflect on my past and how was it that I wound up in a career as a professor and not a drug dealer or stickup kid. It made me think of the individuals who share their stories with researchers and what obligation we have to tell the story correctly while at the same time attempt to uplift marginalized communities. It made me aware that only someone in the shoes similar to Randol Contreras could tell this story because of his positioning in the South Bronx and in the lives of the participants. Although the story of 
the rise and fall of drug dealers is a popular genre in movies and music, Dr. Contreras shines in providing readers a greater level of complexity and nuance to understand these experiences.

\section{References}

Bourgois, P. (1995). In search of respect: Selling crack in el barrio. New York, NY: Cambridge University Press.

Katz, J. (1988). Seductions of crime: Moral and sensual attractions in doing evil. New York, NY: Basic Books. 